\title{
Fertilizer-use Efficiency of Farmers Using Manure in Liaozhong County, China
}

\author{
Eiichi KUSANO ${ }^{1 *}$, Changbin YIN ${ }^{2}$ and Hsiaoping CHIEN ${ }^{1}$ \\ ${ }^{1}$ Social Sciences Division, Japan International Research Center for Agricultural Sciences (Tsukuba, \\ Ibaraki 305-8686, Japan) \\ ${ }^{2}$ Chinese Academy of Agricultural Sciences (Beijing 100081, China)
}

\begin{abstract}
Surplus use of agricultural inputs such as fertilizers and pesticides that cause land and water pollution have been a serious problem in China. This study investigated surplus fertilizer use for corn, rice, vegetable, and tomato farming in terms of farm management by the smoothed bootstrap levels. Higher surplus fertilizer use was observed for farmers using manure, although their chemical fertilizer use levels were similar or lower. It was also confirmed that the input value of both purchased and selfmade manures was more unstable than that of chemical fertilizers.
\end{abstract}

Discipline: Agricultural economics

Additional key words: agricultural waste, circular agriculture, DEA, manure

\section{Introduction}

Surplus agricultural inputs such as fertilizers and pesticides that cause land and water pollution have been a serious problem in China. The Chinese government has tried to ease this problem through several policies, including country-wide soil analysis, subsidies for using agricultural waste, and standardization of livestock farming. The cyclical use of agricultural waste and conservation of resources, also known as circular agriculture (CA), has also spread in recent years $(\mathrm{Li}$ 2011). In this context, the utilization of agricultural waste is being promoted.

Recent studies have focused on inefficient or surplus fertilization by farmers who use agricultural waste, organic fertilizer, or manure at several sites (Marchand \& Guo, 2014). However, these studies tend to focus on fertilizers or their components. Little is known empirically whether farmers use appropriate manure as compared with their production values. Thus, this study investigates the relationship between inefficient fertilization and manure in terms of cost. Specifically, we measured the value of surplus fertilizer reflecting the inefficiency of agricultural management by a benchmarking method. We then examined the relationships among the inputted manure, chemical fertilizer, and surplus fertilizer. Through these investigations, this study reveals issues related to the spread of CA in China and those related to the utilization of agricultural waste.

\section{Study area}

Liaozhong County, the focus area of this study, is one of three counties in Shenyang, the capital city of Liaoning Province. In 2014, Liaozhong County covered 1,645 $\mathrm{km}^{2}$ and encompassed 134,187 households and 393,743 people in its rural area (SMBS 2015). The county is active in the production of corn, rice, vegetables, chicken, and lean pork, and it is a national-level demonstration county for the standardization of agriculture (MOA 2013). Liaozhong County's primary products are representative of agricultural data in northeast China.

The Chinese government selected Liaozhong County as a national-level ecological county in 2011(De Jong et al. 2016). In an ecological county, large-scale livestock farmers must follow the discharge standard of pollutants issued by the Chinese government, and may appropriately use or dump animal waste. On the other hand, it is reported that small-scale livestock farmers can cause water and soil pollution by directly using animal waste for soil cultivation.

*Corresponding author: e-mail kusano11@affrc.go.jp

Received 2 May 2018; accepted 28 September 2018. 


\section{Data}

We used household data collected by the Institute of Agricultural Resource and Regional Planning, as well as data obtained from semi-structured face-toface interviews conducted by the Chinese Academy of Agricultural Sciences (CAAS) in Liaozhong County in 2014. Staff members and trained graduate students of CAAS conducted interviews by using questionnaires in each village or district. The questionnaires included information about farmers' characteristics and agricultural management of all crops and livestock in 2013.

CAAS collected data from six out of the 15 towns in the county. In each town, one to two villages or districts were selected and 20-80 households were interviewed in each village. In total, surveyed data were collected from 10 out of 209 villages and districts. A total of 525 households were surveyed, among which 495 were considered valid for the management analysis.

An important feature of this dataset is its comprehensiveness because it includes detailed data on crops, livestock, fertilizers, and manures. For example, it stores detailed data of purchased and self-made manures made from cattle, pig, horse, and others for individual crops, apart from data regarding animal excrement from livestock farmers. In this paper, the "Self-made manure" refers to the input for individual crops without wasted excrement. On the other hand, there are several limitations in this dataset. First, the collected data only reflect information of a single year. Soil nutrient accumulated over several years cannot be rigorously analyzed. Second, information about the maturity or quality of manure was not collected.

The collected data depict the general situation of the surveyed area. Farmland area was held by $79 \%$ surveyed farmers, averaging $0.67 \mathrm{ha} /$ household. Corn farmers accounted for the largest group (57\%) of surveyed farmers, followed by rice $(29 \%)$, tomato $(8 \%)$, celery $(6 \%)$, lettuce $(5 \%)$, and other vegetable and fruit farmers. In this study, we focused on corn, rice, whole vegetable, and tomato farmers. Vegetable data were calculated by adding up the data of individual vegetables.

We estimated production values of agricultural products; input values of chemical fertilizers, manures, and other inputs; and labor index based on the surveyed data. The production values were estimated as production quantity multiplied by the farm-gate prices of each product. Similarly, input values of purchased chemical fertilizer and manures were estimated from the input quantities of each farmer multiplied by their actual purchased prices or the average prices of the belonging village according to data availability. We assumed two types of prices for selfmade manure. First, we established the price of self-made manure to the same value as the average by animal type of purchased manure in the belonging village, town, or county according to data availability because we could not ignore the opportunity cost to carry, produce, and spread animal excrement and manure. Second, we assumed the price of self-made manure was zero. The actual value of the self-made manure is thought to be between those two prices. Analyses based on two assumptions showed similar results. Thus, we report the results obtained from the first assumption in this paper. The value of the other inputs is the sum of machine operation, seed, pesticide, electricity, and labor fees. The labor index was estimated as the number of agricultural labor multiplied by the percentage of each labor's working days in the year. Household data containing a zero for production value, input value, or labor index were excluded from the efficiency estimation.

\section{Method}

The major purpose of this study is the exploration of the relationship between surplus fertilizer and input of manure. First, management efficiencies of corn, rice, vegetables, and tomatoes are estimated by smoothed bootstrap data envelopment analysis (DEA), a nonparametric method of benchmarking (See Appendix 1). To explain the estimated inefficiency, we illustrate histograms of the surplus fertilizer and the share of its components, namely chemical fertilizer, purchased manure, and self-made manure. Next, distributions of surplus fertilizer and all other data belonging to farmers who use manure were compared against those of other farmers. The normality of each distribution was checked by the Jarque-Bera test. Then, $t$-test or Mann-Whitney $U$-test was used to determine whether distributions belonging to the two kinds of farmers were the same.

The method of this study is characterized by the treatment of data which does not follow the normal distribution. To describe the actual situation of farmers more faithfully, we show the results of the normality test. This is also one of the reasons why we use DEA rather than stochastic frontier analysis (SFA). The normality of the residuals obtained from SFA assuming each of the trans-log and Cobb-Douglass production functions was rejected by the Jarque-Bera test in the preliminary analysis. Furthermore, we consider the relationship between the surplus fertilizer and input of mature based on histograms, statistical tests, and supplemental information, instead of the widely used two-stage regression approach, which employs ordinary least squares or Tobit regression as the second stage. 


\section{Results}

Figure 1 illustrates histograms of surplus fertilizer. The lower half of Figure 1 shows the proportion of chemical fertilizer, purchased manure, and self-made manure in each range of the upper histogram. The majority of farmers use surplus fertilizer of 500-1,000 CNY/ha for corn, 1,000-1,200 CNY/ha for rice, 2,000-6,000 CNY/ha for vegetables, and 6,000-12,000 CNY/ha for tomatoes.
Chemical fertilizers account for a large part of surplus fertilizer used by corn and rice farmers. The proportion of corn farmers using manure increases with greater surplus fertilizer. The histograms of vegetable and tomato farmers show high proportions of purchased manure constituting surplus fertilizer.

Table 1 shows modes of management data including the estimated surplus fertilizer of farmers who use manure and the data farmers who use other products. As

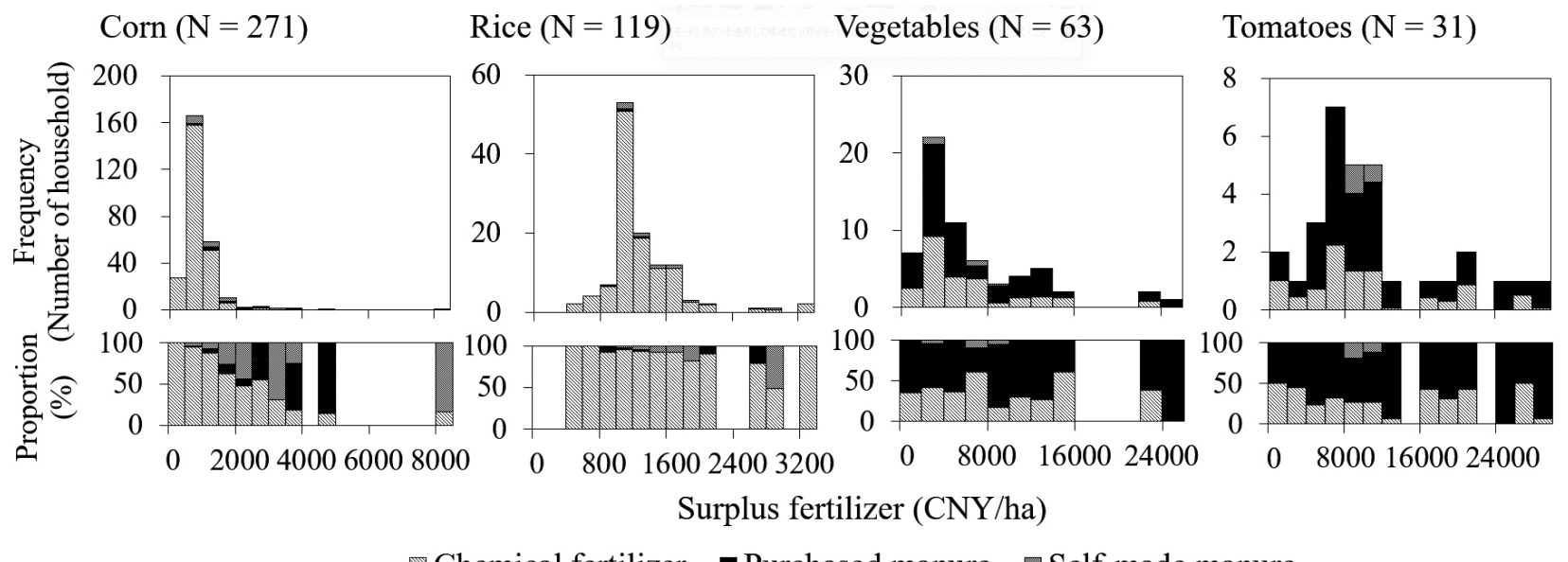

$\mathbb{Q}$ Chemical fertilizer $\square$ Purchased manure $\square$ Self-made manure

Fig. 1. Histograms of surplus fertilizer and share of its components

Notes: The range of X axis in each histogram is $500 \mathrm{CNY} /$ ha (corn), $200 \mathrm{CNY} /$ ha (rice), and 2,000 CNY/ha (both vegetables and tomatoes), respectively. The vegetables include tomatoes, celery, lettuce, cowpeas, kidney beans, cucumbers, Chinese celery, groundnuts, soybeans, bitter gourds, eggplants, and others in order of number of cultivation farmers (the same applies to the following tables and figures).

Table 1. Comparison of variables of farmers using and not using manure

\begin{tabular}{|c|c|c|c|c|c|c|c|c|c|c|c|c|}
\hline & \multicolumn{4}{|c|}{ Corn } & \multicolumn{4}{|c|}{ Rice } & \multicolumn{4}{|c|}{ Vegetables } \\
\hline & Manure & Non-manure & \multicolumn{2}{|l|}{ U-stat } & Manure & Non-manure & \multicolumn{2}{|l|}{ U-stat } & Manure & Non-manure & \multicolumn{2}{|l|}{ U-stat } \\
\hline \multicolumn{13}{|c|}{ Including the price data of self-made manure } \\
\hline Production value $(\mathrm{CNY} / \mathrm{ha})$ & 17,366 & 19,500 & 3,713 & ** & 25,350 & 25,200 & 847 & & $117,262^{* * *}$ & 52,500 & 194 & \\
\hline Surplus fertilizer (CNY/ha) & $2,638^{* * *}$ & $1,144^{* * *}$ & 936 & $* * *$ & 2,168 & $1,249^{* * *}$ & 421 & *** & $2,020^{* * *}$ & 1,767 & 59 & $* * *$ \\
\hline Fertilizer (CNY/ha) & $3,976^{* * *}$ & $2,100^{* * *}$ & 764 & $* * *$ & 2,886 & $3,150^{* * *}$ & 321 & $* * *$ & $9,465^{* * *}$ & 4,350 & 59 & *** \\
\hline Chemical fertilizer & $1,980^{* *}$ & $2,100^{* * *}$ & 5,833 & $* * *$ & 1,609 & $3,150^{* * *}$ & 1,162 & $* * *$ & $1,200^{* * * *}$ & 4,350 & 198 & \\
\hline Manure & $1,500^{* * *}$ & - & - & & 1,263 & - & - & & $8,400^{* * * *}$ & - & - & \\
\hline Other inputs (CNY/ha) & $1,200^{* * *}$ & $2,955^{* * *}$ & 5,302 & & 5,025 & 8,250 & 894 & & $46,575^{* * *}$ & 14,063 & 119 & \\
\hline Labor index (person/ha) & $2.00^{* * *}$ & $0.50^{* * *}$ & 4,007 & & $0.21^{* * *}$ & $0.30^{* * *}$ & 981 & & $5.00^{* * *}$ & 30.00 & 260 & $* *$ \\
\hline Planted area (ha) & $0.67^{* * *}$ & $0.40^{* * *}$ & 5,261 & & 0.40 & $0.20^{* * *}$ & 658 & & $0.20^{* * *}$ & 0.07 & 89 & $*$ \\
\hline Number of observations & 40 & 231 & - & & 16 & 103 & - & & 57 & 6 & - & \\
\hline \multicolumn{13}{|c|}{ Excluding the price data of self-made manure } \\
\hline Production value $(\mathrm{CNY} / \mathrm{ha})$ & 22,800 & 19,500 & 1,719 & & 23,400 & $25,200^{*}$ & 283 & & $117,262^{* * *}$ & 77,344 & 204 & \\
\hline Surplus fertilizer (CNY/ha) & $2,287^{* *}$ & $1,234^{* * *}$ & 141 & $* * *$ & 2,002 & $1,305^{* * *}$ & 231 & & $1,865^{* * *}$ & 713 & 55 & *** \\
\hline Fertilizer (CNY/ha) & $5,258^{* *}$ & $2,100^{* * *}$ & 72 & *** & 3,038 & $2,520^{* * *}$ & 206 & & $9,465^{* * *}$ & 870 & 57 & *** \\
\hline Chemical fertilizer & 2,273 & $2,100^{* * *}$ & 2,006 & & 1,538 & $2,520^{* * *}$ & 379 & & $1,200^{* * *}$ & 870 & 198 & \\
\hline Manure & $1,500^{* *}$ & - & 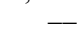 & & 1,200 & - & - & & $2,250^{* * *}$ & - & - & \\
\hline Other inputs $(\mathrm{CNY} / \mathrm{ha})$ & $4,313^{* * *}$ & $2,955^{* * *}$ & 1,953 & & 7,448 & 8,250 & 279 & & $46,575^{* * *}$ & 14,063 & 133 & \\
\hline Labor index (person/ha) & $2.00^{*}$ & $0.50^{* * *}$ & 1,945 & & 0.25 & $0.30^{* * *}$ & 414 & - & $5.00^{* * *}$ & 30.00 & 284 & $*$ \\
\hline Planted area (ha) & 0.27 & $0.40^{* * *}$ & 2,010 & & 2.20 & $0.20^{* * *}$ & 162 & & $0.20^{* * * *}$ & 0.07 & 114 & * \\
\hline Number of observations & 15 & 253 & - & & 5 & 113 & - & & 56 & 7 & - & \\
\hline
\end{tabular}

Notes: $* * * 0.01, * *<0.05, *<0.1$. "Manure" and "Non-manure" denote farmers' manure and non-manure use, respectively. Values in those columns are Bickel's half-range mode estimator (bandwidth $=0.3$; the same applies hereinafter). Stars in the columns "Manure" and "Non-manure" denote results of the Jarque-Berra test. Values and stars in the column "U-stat" are results of Mann-Whitney's $U$-test. Comparison of the tomato data was omitted because only one tomato farmer does not use manure. $1 \mathrm{CNY} \approx 0.16 \mathrm{USD}$. 
a reference, the values calculated from data without the value of self-made manure are also shown in Table 1 . The results of the Jarque-Bera test on those data indicate that the null hypothesis of the normal distribution is rejected in many commodities and items. Thus, Bickel's halfrange mode estimator (Bickel, 2002) is used to describe each distribution rather than the mean and median. Furthermore, the Mann-Whitney U-test is primarily used to test the null hypothesis that the distributions of the two kinds of farmers are the same.

First, we focus on the results obtained from the estimation including the price data of self-made manure. In the case of corn, the null hypothesis is rejected for the values of production and surplus, total, and chemical fertilizers. Mode values suggest that the farmers using manure input less chemical fertilizer, and input more total and surplus fertilizers. Similarly, rice farmers who use manure use significantly less chemical and total fertilizers and use more surplus fertilizer. Vegetable farmers using manure inputted significantly more manure than total and surplus fertilizers. Overall, in spite of the similar or lower level of chemical fertilizer, farmers using manure tend to input a higher level of surplus fertilizer. As for the labor index, planted area, and other parameters, there were almost no significant differences at the $5 \%$ level between the two groups.

The estimation results without the price data of self-made manure indicate significantly higher values of total and surplus fertilizers for corn and vegetables by farmers using manure. Values of mode imply a similar interpretation for rice and vegetables, although their samples are too small to provide convincing evidence.

\section{Discussion}

These results suggest a low substitutability of chemical fertilizer compared to manure as the reason for surplus fertilization. Figure 2, which illustrates scatter plots of manure and chemical fertilizer, supports this inference. Corn farmers who do not use manure mainly input $0-5,000 \mathrm{CNY} /$ ha of chemical fertilizer. Chemical fertilizer hovers within this range even when the value of manure increases. The total value of fertilizer surpasses 5,000 CNY/ha as the manure input increases. Such relationships are observed for tomatoes as well.

Inefficient input of manure would occur when farmers use this measure to dispose of animal excrements. Table 2 shows many farmers feeding self-made manure to animals. Furthermore, input values of self-made manure for crop production are similar or higher than those of farmers using purchased manure (Table 3). The data suggest that the feeding of self-made manure to animals by farmers can result in surplus fertilization.

On the other hand, Tables 2 and 3 suggest that a number of farmers, regardless of animal feed, input purchased manure that can also cause surplus fertilization, as illustrated in Figure 1. Smaller values of skewness and kurtosis of both purchased and self-made manure indicate a more right-modal and platykurtic distribution as compared with chemical fertilizers (Table 3 ). In other words, the input value of manure is less stable than that of chemical fertilizer. One of the reasons for such a distribution could be the unstable effect of manure input and/or insufficient farmer knowledge about such surplus fertilization (De Ponti et al. 2012, Ponisio et al. 2014). Thus, a focus on technical improvement and stabilization of manure quality can decrease surplus fertilization. Other important measures can include dissemination of information on the fertilizer effect of manure and its substitutability for chemical fertilizer. For example, technical training and an organic fertilizer input manual provided to village committees and individual farmers would embody such intervention.

Although we mainly focused the surplus fertilization
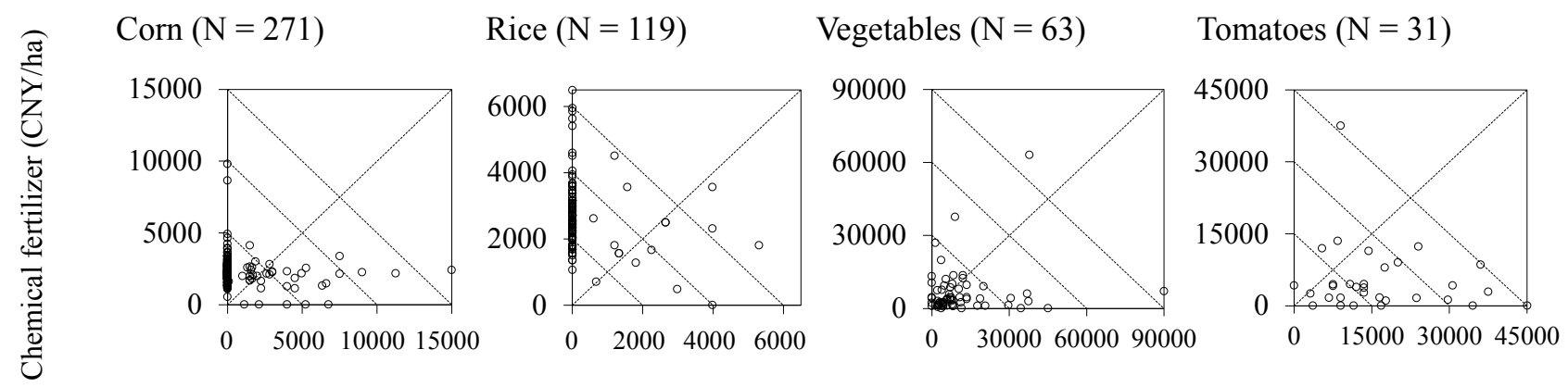

Manure (CNY/ha)

Fig. 2. Scatter plot of manure and chemical fertilizer inputs 
of farmers using manures in this paper, soil pollution caused by the dumping of animal excrement is another important issue. As shown in Table 4, some pig farmers waste excrements of approximately $100 \mathrm{t}$. Although this does not immediately suggest inappropriate dumping of the excrements, dissemination of appropriate procedure to dispose manure would also be important in the realization of CA in China.

\section{Conclusion}

We measured surplus fertilizer inputted for corn, rice, vegetables, and tomatoes in terms of farm management by the smoothed bootstrap DEA. We also investigated relationships between surplus fertilizer and values representing the management of inputs such as manure and chemical fertilizer. The results of this study show

Table 2. Number of households feeding animals and using manure

\begin{tabular}{lrrrr}
\hline \hline & Corn & Rice & Vegetables & Tomatoes \\
\hline Number of producers & 281 & 143 & 83 & 37 \\
\hline Using purchased cattle manure & 8 & 2 & 35 & 2 \\
Feeding cattle & 9 & 3 & 0 & 2 \\
Using self-made cattle manure & 8 & 3 & 2 & 0 \\
Using purchased cattle manure & 1 & 0 & 22 & 3 \\
Using purchased pig manure & 7 & 2 & 2 & 2 \\
Feeding pigs & 7 & 4 & 2 & 2 \\
Using self-made pig manure & 7 & 4 & 0 & 0 \\
Using purchased pig manure & 2 & 0 & & 2 \\
\hline
\end{tabular}

Note: The total number of observed cattle and pig feeders are 28 and 53, respectively.

Table 3. Fertilizer input per unit area (CNY/ha)

\begin{tabular}{|c|c|c|c|c|c|c|c|c|c|c|c|c|c|}
\hline & & & Mean & Median & Mode & S.D. & Max & Min & $\begin{array}{c}\text { Skew- } \\
\text { ness }\end{array}$ & Kurtosis & $\begin{array}{c}\text { Jarque } \\
\text {-Bera stat }\end{array}$ & Obs. & $\begin{array}{l}\text { Propor- } \\
\text { tion (\%) }\end{array}$ \\
\hline \multicolumn{14}{|l|}{ Corn } \\
\hline Chemica & 1 fertilizer & & 2,332 & 2,250 & 2,100 & 875 & 9,791 & 540 & 3.89 & 27.88 & $9,541.75^{* * *}$ & 269 & 96 \\
\hline \multirow{6}{*}{ Manure } & Purchased & Cattle & 3,831 & 3,188 & 1,500 & 2,484 & 7,500 & 1,500 & 0.29 & -1.86 & 0.93 & 8 & 3 \\
\hline & & Pig & 4,421 & 3,000 & 788 & 4,918 & 15,000 & 750 & 1.29 & 0.15 & 3.57 & 7 & 2 \\
\hline & & Others & 1,575 & 1,575 & 1,575 & 106 & 1,650 & 1,500 & 0.00 & -2.75 & 0.33 & 2 & 1 \\
\hline & Made & Cattle & 3,444 & 2,813 & 1,669 & 1,934 & 7,500 & 994 & 0.67 & -0.75 & 1.30 & 13 & 5 \\
\hline & & Pig & 2,757 & 1,778 & 1,538 & 2,988 & 11,250 & 79 & 1.82 & 2.55 & $15.13^{* * *}$ & 12 & 4 \\
\hline & & Others & 2,500 & 3,000 & 3,000 & 866 & 3,000 & 1,500 & -0.38 & -2.33 & 0.53 & 3 & 1 \\
\hline \multicolumn{14}{|l|}{ Rice } \\
\hline Chemica & 1 fertilizer & & 2,697 & 2,550 & 2,520 & 1,015 & 6,480 & 480 & 1.13 & 2.28 & $54.37^{* * *}$ & 120 & 84 \\
\hline \multirow{6}{*}{ Manure } & Purchased & Cattle & 638 & 638 & 638 & 53 & 675 & 600 & 0.00 & -2.75 & 0.33 & 2 & 1 \\
\hline & & Pig & 1,500 & 1,500 & 1,500 & 424 & 1,800 & 1,200 & 0.00 & -2.75 & 0.33 & 2 & 1 \\
\hline & & Others & 1,200 & 1,200 & 1,200 & - & - & - & - & - & - & 1 & 1 \\
\hline & Made & Cattle & 3,646 & 3,977 & 3,977 & 574 & 3,977 & 2,983 & -0.38 & -2.33 & 0.53 & 3 & 2 \\
\hline & & Pig & 2,306 & 2,250 & 1,326 & 1,100 & 3,978 & 1,326 & 0.42 & -1.68 & 0.48 & 5 & 3 \\
\hline & & Others & 1,563 & 1,563 & 1,563 & - & - & - & - & - & - & 1 & 1 \\
\hline \multicolumn{14}{|l|}{ Vegetables } \\
\hline Chemica & 1 fertilizer & & 6,654 & 3,825 & 1,200 & 9,698 & 63,000 & 540 & 3.83 & 17.44 & $1,006.24^{* * *}$ & 62 & 75 \\
\hline \multirow{6}{*}{ Manure } & Purchased & Cattle & 9,824 & 7,200 & 4,500 & 10,193 & 45,000 & 764 & 2.06 & 3.55 & 49.52 *** & 35 & 42 \\
\hline & & Pig & 11,351 & 6,375 & 4,500 & 19,045 & 90,000 & 1,909 & 3.29 & 10.40 & $171.28^{* * *}$ & 22 & 27 \\
\hline & & Others & 6,557 & 5,400 & 3,596 & 4,380 & 16,000 & 1,125 & 0.69 & -0.69 & 1.63 & 16 & 19 \\
\hline & Made & Cattle & - & - & - & - & - & - & - & - & - & 0 & 0 \\
\hline & & Pig & 14,025 & 14,025 & 14,025 & 8,167 & 19,800 & 8,250 & 0.00 & -2.75 & 0.33 & 2 & 2 \\
\hline & & Others & 2,875 & 2,875 & 2,875 & 884 & 3,500 & 2,250 & 0.00 & -2.75 & 0.33 & 2 & 2 \\
\hline \multicolumn{14}{|l|}{ Tomatoes } \\
\hline Chemica & 1 fertilizer & & 6,231 & 4,095 & 4,500 & 7,272 & 37,500 & 1,035 & 2.95 & 9.80 & $175.04^{* * *}$ & 27 & 73 \\
\hline \multirow[t]{6}{*}{ Manure } & Purchased & Cattle & 13,030 & 9,281 & 7,500 & 11,136 & 45,000 & 3,150 & 1.56 & 1.35 & $14.14^{* * *}$ & 24 & 65 \\
\hline & & Pig & 5,625 & 4,500 & 4,500 & 1,949 & 7,875 & 4,500 & 0.38 & -2.33 & 0.53 & 3 & 8 \\
\hline & & Others & 7,575 & 7,500 & 7,500 & 2,344 & 10,500 & 3,375 & -0.38 & -1.09 & 0.44 & 9 & 24 \\
\hline & Made & Cattle & - & - & - & - & - & - & - & - & - & 0 & 0 \\
\hline & & & 18,150 & 18,150 & 18,150 & 2,333 & 19,800 & 16,500 & 0.00 & -2.75 & 0.33 & 2 & 5 \\
\hline & & Others & - & - & - & - & - & - & - & - & - & 0 & 0 \\
\hline
\end{tabular}

Notes: $* * * 0.01, * *<0.05, *<0.1$. Denominator of the proportion is the number of households cultivating each product (corn $=281$, rice $=143$, vegetables $=83$, tomatoes $=37$ ). Mode is the Bickel's half-range mode estimator. Kurtosis is the excess kurtosis. 
Table 4. Usage of animal excrement

\begin{tabular}{|c|c|c|c|c|c|c|}
\hline & \multicolumn{2}{|c|}{ Cattle } & \multicolumn{2}{|c|}{ Pig } & \multicolumn{2}{|c|}{ Chicken and chick } \\
\hline & Mode & Obs. & Mode & Obs. & Mode & Obs. \\
\hline Number (head) & $4^{*}$ & 28 & $2^{* *}$ & 53 & $3,000^{* *}$ & 47 \\
\hline \multicolumn{7}{|l|}{ Animal excrement $(\mathrm{t})$} \\
\hline for waste & 0 & 0 & 104 & 11 & 235 & 3 \\
\hline for self-use manure & $40^{*}$ & 11 & $2^{* *}$ & 18 & 2 & 8 \\
\hline for sale or give away & 2,008 & 17 & $190^{* *}$ & 29 & $77^{* *}$ & 34 \\
\hline
\end{tabular}

Notes: $* * *<0.01, * *<0.05, *<0.1$. Stars denote results of the Jarque-Berra test. Mode is the Bickel's half-range mode estimator.

that a certain proportion of farmers show a tendency to input surplus fertilizer. A higher level of surplus fertilizer was observed for farmers inputting manure, although they use a similar or lower level of chemical fertilizer. Such a tendency seems to exist regardless of whether the estimation includes or excludes self-made manure.

It was confirmed that farmers feeding animals tend to use a certain value of self-made manure as mentioned in past studies. However, farmers who do not feed animals also use purchased manure for their crop production, especially for vegetables. The input values of both purchased and self-made manures were more unstable than those for chemical fertilizers according to the distributions of those fertilizers. Such instability of manure input was discussed in line with its quality and information about the effect of fertilizers in this study. We suggested technical improvement and stabilization of manure quality, and dissemination of information on fertilizer effects to decrease the uncertainty in the input. Extension of regional policies to disseminate knowledge and techniques about fertilization to farmers can be one option in easing surplus fertilization.

This study has several limitations. The sample size of rice and tomatoes, representatives of mono-cropping in agriculture, are too small to obtain usable data. Furthermore, factors related to fertilization should be incorporated in the analysis. As an example, incorporating fertilizer prices may result in beneficial information regarding surplus input. Price data including labor and land will enable exploration into the issue of the use of an inappropriate input mix reflected by slacks (see Appendix 2) by estimating cost efficiency of each DMU (Ferrier \& Lovell, 1990).

Despite these limitations, this study contributes to understanding how and why farmers use surplus fertilizer. Our discussion sheds light on problems of agricultural waste utilization and offers insight into further dissemination of CA.

\section{References}

Besstremyannaya, G. \& Simm, J. (2015) Robust non-parametric estimation of cost efficiency with an application to banking industry. CEFIR/NES Working Paper Series, Working Paper No 217, 1-26.

Bickel, D. R. (2002) Robust estimators of the mode and skewness of continuous data. Comput. Stat. Data An., 39, 153-163.

Bogetoft, P \& Otto, L. (2011) Benchmarking with DEA, SFA, and $R$. Springer.

De Jong, M. et al. (2016) Eco city development in China: Addressing the policy implementation challenge. J Clean Prod., 134, 31-41.

De Ponti, T. et al. (2012). The crop yield gap between organic and conventional agriculture. Agr. Syst., 108, 1-9.

Ferrier, G.D \& Lovell, C.A.K. (1990) Measuring cost efficiency in banking: Econometric and linear programming evidence, J Econom., 46, 229-245.

Li, Y. (2011) Innovation of China's circular agricultural development in the perspective of low carbon economy. Asian Agricultural Research, 3, 5-8.

Marchand, S. \& Guo, H. (2014) The environmental efficiency of non-certified organic farming in China: A case study of paddy rice production. China Economic Review, 31, 201216.

MOA: Ministry of Agriculture and Rural Affairs of the People's Republic of China, National Modern Agriculture Development Plan (2011-2015) III. http://english.agri.gov. cn/hottopics/five/201304/t20130421_19480.htm

Ponisio, L. C. et al. (2014) Diversification practices reduce organic to conventional yield gap. Proc. R. Soc., Ser. B, Biol. Sc., Lond., 282, 1-7.

Simar, L. \& Wilson, P. W. (1998) Sensitivity analysis of efficiency scores: How to bootstrap in nonparametric frontier models. Manage. Sci., 44, 49-61.

Simar, L. \& Wilson, P. W. (2011) Estimation and inference in nonparametric frontier models: Recent developments and perspectives. Econometrics, 5, 183-337.

SMBS: Shenyang Municipal Bureau of Statistics (2015) Shenyang Statistical Yearbook 2015. Shenyang Municipal Bureau of Statistics. [In Chinese] 


\section{Appendix 1. Smoothed bootstrap data envelopment analysis}

We used smoothed bootstrap DEA to estimate surplus input following Simar \& Wilson (1998, 2011). The inputoriented Farrell efficiency under the assumption of variable returns to scale for a given decision-making unit (DMU) ( $x_{k}$, $y_{k}$ ) belonging to the convex hull of $\left(x_{i}, y_{i}\right)$ is estimated by:

$\hat{\theta}_{k}=\min \left\{\theta \mid y_{k} \leq \sum_{i=1}^{n} \gamma_{i} y_{i} ; \theta x_{k} \geq \sum_{i=1}^{n} \gamma_{i} x_{i} ; \theta>0 ; \sum_{i=1}^{n} \gamma_{i}=1 ; \gamma_{i} \geq 0, i=1, \ldots, n\right\}$,

where $\theta$ denotes the Farrell input measures of efficiency, $\hat{\theta}$ denotes the estimator of $\theta, y$ denotes production value per unit area, and $x \in \mathrm{R}^{\mathrm{s} \times \mathrm{n}}(\mathrm{s}=1,2,3)$ denotes inputted fertilizer value, other input values, and labor index per unit area. The smoothed bootstrap is used to avoid a naive DEA inward-bias of $\partial \widehat{X(y)}$, estimated efficiency boundary of input set for $y$ denoted by $X(y)$, and to avoid over-generation of efficient units with $\hat{\theta}_{k}=1$ by the naive bootstrap (Simar $\&$ Wilson, 1998). The bias-corrected efficiency scores are described as:

$\tilde{\theta}_{k}=\hat{\theta}_{k}-\widehat{b i a s}_{k}$,

and the bias is described as:

$\widehat{\operatorname{bias}}_{k}=\frac{1}{B} \sum_{b=1}^{B} \hat{\theta}_{k b}^{*}-\hat{\theta}_{k}$,

where $\hat{\theta}_{k b}^{*}$ denotes the bootstrap estimate of $\hat{\theta}_{k}$. B denotes 1,000 bootstrap iterations in this study. We followed Simar \& Wilson (1998) and selected Silverman's bandwidth method to smooth the empirical distribution of $\hat{\theta}_{k b}^{*}$ for the resampling. The surplus input of each DMU is estimated by $x_{k}-x_{k} \tilde{\theta}_{k}$. Package "rDEA" for R developed by Besstremyannaya \& Simm (2015) was used for the smoothed bootstrap DEA.

\section{Appendix 2. Output and input slacks of DEA}

Even if DMUs decrease inputs to reach the frontier line without changing the composition of inputs and realize Farrell efficient production, that may be able to increase output $y$ or decrease input $x$ as compared with other reference DMUs on the frontier line. Those output and input slacks suggest insufficient production and surplus inputs of Farrell efficient DMUs, respectively.

In this Appendix, as reference information, we show output slacks (production value) and input slacks (fertilizer, labor index, and other inputs) estimated by using a common method called two-stage procedures (Bogetoft \& Otto 2011, pp.127-129).

The table of slacks suggests that even if Farrell efficiency is achieved, there are many DMUs having a potential to increase production value. A certain number of DMUs having input slacks implies the existence of an inappropriate input mix, especially of the other inputs to rice, vegetables, and tomatoes.

Table 5. Non-zero output and input slacks

\begin{tabular}{|c|c|c|c|c|c|c|c|c|}
\hline & \multicolumn{4}{|c|}{ Proportion of DMU having non-zero slacks (\%) } & \multicolumn{4}{|c|}{ Mode of non-zero slacks } \\
\hline & Corn & Rice & Vegetables & Tomatoes & Corn & Rice & Vegetables & Tomatoes \\
\hline Production value & 52 & 54 & 11 & 42 & 1,440 & 587 & 2,803 & 22,766 \\
\hline Fertilizer & 9 & 8 & 25 & 13 & 51 & 502 & 150 & 3,007 \\
\hline Labor index & 12 & 8 & 3 & 6 & 0 & 2 & 7 & 2 \\
\hline Other inputs & 6 & 18 & 13 & 16 & 226 & 2,565 & 1,436 & 51,341 \\
\hline
\end{tabular}

Notes: Unit of the mode for production value, fertilizer, and other inputs are CNY/ha. That of labor index is person/ha. Data including the price of self-made manure was used for the estimation. The number of observations is the same as those of Figures 1 and 2. Mode is the Bickel's half-range mode estimator. 